\title{
Treatment Refractory Hypothyroidism Requiring High Dose Thyroxin Replacement
}

\author{
Faria Afsana* \\ Department of Endocrinology BIRDEM General Hospital, Bangladesh
}

Submission: December 12, 2020; Published: January 11, 2021

*Corresponding author: Faria Afsana, Assistant Professor, Dept. of Endocrinology BIRDEM General Hospital, Room 1320,122 Kazi Nazrul Islam Avenue, Shahbag Dhaka, Bangladesh

\section{Abstract}

A group of hypothyroid patients fails to achieve euthyroidism despite high doses of levothyroxine. These patients are designated as treatment refractory hypothyroidism. The prevalence of treatment-refractory hypothyroidism is not established. Noncompliance is one of the major issues in such cases .Other than noncompliance; impaired absorption due to gastrointestinal disease is a possibility. To achieve the target TSH or euthyroidism commonly the dose of levothyroxine is gradually increased but it may increase few adverse outcome, cost of investigation, follow up and treatment. Suspected patients should undergo a systematic approach for evaluation and management of this condition. In such a situation, there is a need to search for causes of decreased absorption of thyroxine or increased demand for thyroxine .This evaluation may help to reveal few underlying diseases and management of that disease may help to cure the refractoriness of levothyroxine replacement. An alternative formulation of levothyroxine may be prescribed to overcome the situation before going for detailed investigation. This article is emphasizing the diagnostic approach and management plan of such cases of treatment refractory hypothyroidism.

Keywords: Hypothyroidism; Treatment refractory; Levothyroxine; Noncompliance

\section{Introduction}

Primary hypothyroidism is defined to be treatment refractory when there is clinical or biochemical evidence of hypothyroidism and/or unresolved hypothyroid symptoms, despite increasing dosages of levothyroxine $>1.9 \mu \mathrm{g} / \mathrm{kg} /$ day [1]. In this situation further thyroxine dose increase may not always solve the issue and patient may remain Clinically and biochemically hypothyroid. Supratherapeutic doses may produce cardiovascular and other side effects. In cases where unexpectedly high doses of thyroxine are required, compliance of the patient should be the first step in evaluation. If the patient is compliant about the dose and timing of thyroxine intake, causes of decreased absorption or increased demand for thyroxine should be searched then [2]. The prevalence of refractory hypothyroidism is not been documented but this condition is increasingly recognized worldwide [2,3]. A finding reported from a study by Vaisman in a multicenter study from Brazil, reveals $28 \%$ of 2292 hypothyroid patients had elevated serum TSH levels inspite of thyroid hormone replacement therapy [4]. Previous studies also show that a good percentage of patients may not achieve euthyroidism despite high dose of levothyroxine [5]. This article highlights the causes of refractory hypothyroidism and approach for its diagnosis and management.

\section{Discussion}

Free T3, Free T4 and TSH are done to evaluate thyroid function .As stated by American Thyroid Association (ATA), TSH is the most reliable marker to see the adequacy of thyroid replacement in hypothyroidism and the therapeutic target should be between 0.4-4.0mIU/L [6]. Hypothyroidism may be classified as over and subclinical according to TSH level. Subclinical hypothyroidism is defined when serum TSH above the upper reference limit, with a normal FT4, on the other hand overt hypothyroidism is typically characterized by an elevated TSH ( $>10 \mathrm{mIU} / \mathrm{L})$ in combination with a subnormal FT4 [7]. After diagnosis of hypothyroidism and starting levothyroxine replacement few patients fail to achieve euthyroidism .These Patients require referral to specialist for evaluation when an unexpectedly high doses of levothyroxine $(>1.9 \mu \mathrm{g} / \mathrm{kg} /$ day) is required, and patient is still experiencing persistent symptoms of hypothyroidism. In such cases causes of refractory hypothyroidism should be searched for

\section{Causes of refractory hypothyroidism}

Following are the conditions that can make patients refractory to the thyroid hormone treatment. 


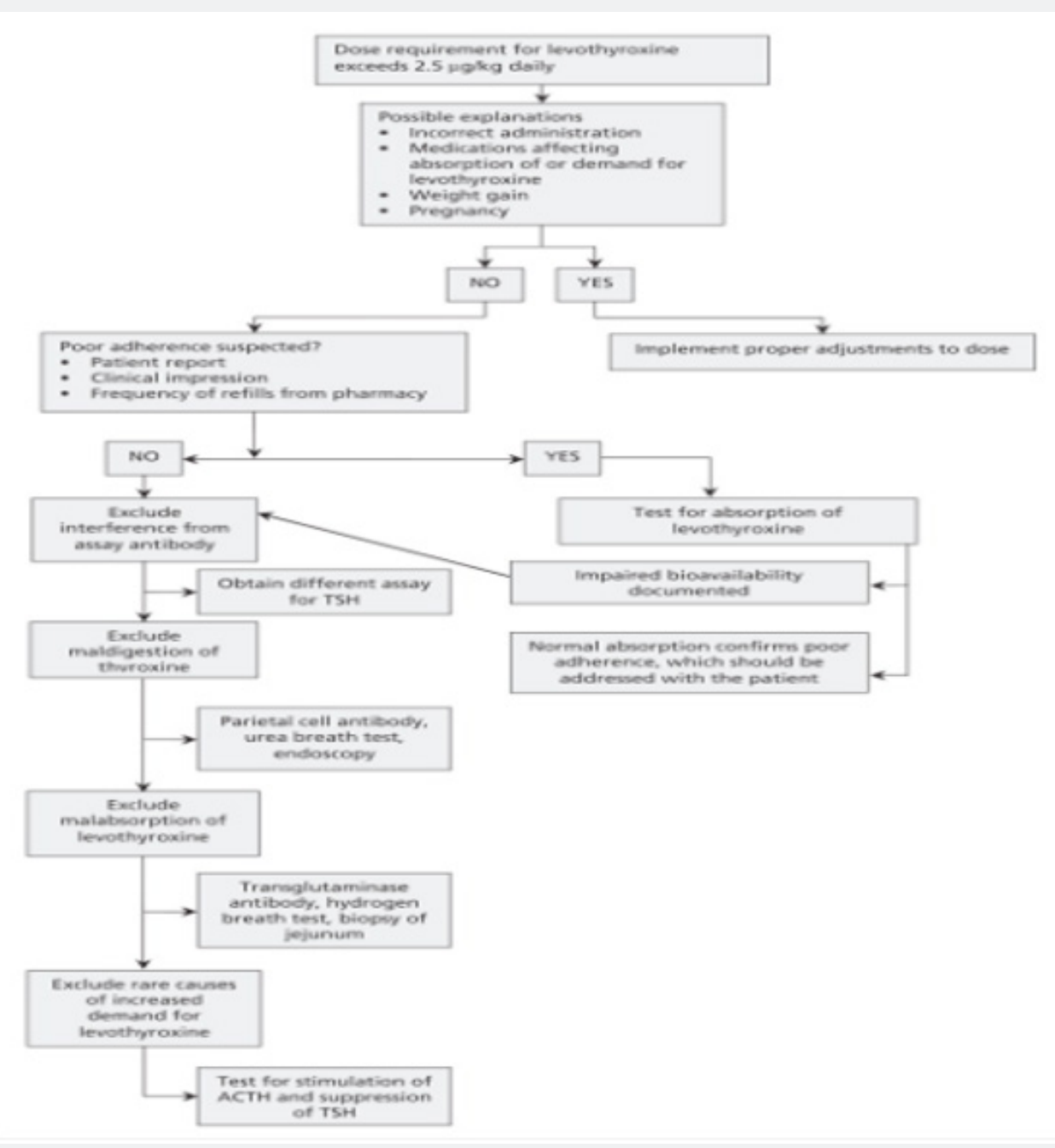

Figure 1: Approach to diagnosis of Refractory hypothyroidism. ACTH=Adrenocorticotropic hormone, TSH=thyroid-stimulating hormone [12].

Non-compliance: Levothyroxine is always to be taken in prebreakfast morning dose at least $30 \mathrm{~min}$ before breakfast .Missed and post meal doses of therapy is a very common issue and decreases bioavailability. Poor compliance with the daily dosing of levothyroxine is one of the most common cause for unusually high doses requirement .As thyroxine has a long halflife, missing a single dose has an influence on thyroid hormone and TSH levels that can extend for several days [8].

Switching to a different group of levothyroxine: Interchange of levothyroxine preparations at the pharmacy has been shown to contribute to sub-optimal management of hypothyroidism and mostly both patients and physicians are very much unaware of it. Detailed history of proper dosing of levothyroxine is very important while evaluating treatment refractory hypothyroidism. In 2010, the American Association of Clinical Endocrinologists (AACE), American Thyroid Association (ATA), and The Endocrine Society (TES) jointly conducted a survey which revealed that the treatment failure or refractoriness to levothyroxine replacement most frequently reported among those who substituted different generics of levothyroxine products throughout the study period. Most of these cases presents with symptomatic and biochemical failure to achieve euthyroidism [9].

Dietary factors/Coadministration of other agents: levothyroxine is absorbed primarily at lower part of small intestine. Several dietary habits including post meal ingestion, co administration of nutritional supplements as iron, calcium and vitamins and medications as proton-pump inhibitors, histamine receptor blockers, cholestyramine may decrease bioavailability of levothyroxine. Improper storage of tablets has been also contributing to levothyroxine malabsorption [1].

Gastrointestinal disorders: In a report from McMillan et al. the prevalence of factors that can affect the absorption and tolerability of levothyroxine was documented. This report reveals that several gastrointestinal diseases as gastroesophageal reflux disease, irritable bowel syndrome, lactose intolerance. 
Helicobacter pylori infection, inflammatory bowel disease, celiac disease, lactose intolerance, atrophic gastritis, gastric bypass, biliary pancreatic diversion, irritable bowel syndrome and gastroparesis are associated with impaired absorption and bioavailability of levothyroxine [10]. If these diseases occur in hypothyroid patients, they seem to require increased need for thyroxine dosage [1].

Pregnancy: During pregnancy there is mostly increase in levothyroxine dose requirement .Women with previously diagnosed hypothyroidism, may need to increase their dose of levothyroxine to prevent hypothyroidism and its adverse pregnancy outcomes. A pregnancy test should be done in all women of reproductive age suspected of having treatment-refractory hypothyroidism [11].The most recent ATA guidelines provide the trimester-specific reference ranges for TSH: The TSH range for each trimester should be defined with a generalized range as follows: $0.1-2.5 \mathrm{mIU} / \mathrm{L}$ for the first trimester, $0.2-3.0 \mathrm{mIU} / \mathrm{L}$ for the second trimester, and $0.3-3.0 \mathrm{mIU} / \mathrm{L}$ for the third trimester" [6]. So levothroxine dose calculation and refractoriness should be considered according to this range in different trimester.

Other disease: Dysfunction in the hypothalamic-pituitarythyroid axis (thyroid hormone resistance) and Addison's disease are the two endocrinopathies that are associated with treatment refractory hypothyroidism. Few studies revealed that cystic fibrosis, amyloidosis, nephrotic syndrome can have a direct effect on the thyroid function and lead to increased levothyroxine requirement [1].

\section{Approach to refractory hypothyroidism}

The most common approach to managing refractory hypothyroidism is to escalate the dose of levothyroxine or change the levothyroxine formulation until euthyroidism is achieved. It sometimes needs considerable trial and error due to narrow therapeutic index of levothyroxine. This approach has several drawbacks also as suprphysiological dose may increase the risk of bone fracture, affects bone mineral density leading to osteoporosis, tachyarythmia, decrease compliance. While managing such cases it is mandatory to confirm the diagnosis and plan of management. (Figure 1) describes the approach to diagnose a patient with refractory hypothyroidism. If a definitive cause is not found inspite of all the steps followed, a clinical test for estimating the absorption of thyroxine may have utility in some patients who have unexpectedly high thyroxine requirements.

This absorption test may be done though it is still not standardized and require complete supervision and require hospitalization. The test involves administration of a single large dose of levothyroxine, followed by monitoring serum thyroxine levels over time [12]. The decision to use an alternative formulation of levothyroxine may be one approach. Recent evidence suggests that either the softgel or liquid alternatives (if available) may eliminate several gastrointestinal factors that contribute to levothyroxine tablet failure and refractory hypothyroidism. These preparations also offer good result in noncompliant patients and patients having swallowing difficulty. Patients with impaired gastric $\mathrm{pH}$ and those with sensitivity to traditional levothyroxine tablets can stand to benefit from these alternative options [1].

\section{Conclusion}

Refractory Hypothyroidism is a rare clinical entity .Situations where there is possibility of therapeutic failure are noncompliance, Gastrointestinal disease (gluten/celiac disease), the effects of other therapeutic agents, improper timing of ingestion relative to meals and foods. Switching to different generic levothyroxine products has also been related to failure to achievement of euthyroidism. The common approach to managing patients with unusual thyroxine needs is to increase the dose of levothyroxine until targeted TSH levels are achieved. This approach can lead to several adverse outcomes as increased bone loss, cardiovascular effects due to prolonged exposure to supratherapeutic doses of levothyroxine. This article recommends a stepwise systematic approach for suspected treatment-refractory hypothyroidism needs to be considered before escalating to supraphysiological dose.

\section{References}

1. Centanni M, Benvenga S, Sachmechi I (2017) Diagnosis and management of treatment-refractory hypothyroidism: an expert consensus report. J Endocrinol Invest 40: 1289-1301.

2. Ramadhan A, Tamilia M (2012) Treatment-refractory hypothyroidism. CMAJ 184: 205-209.

3. Benvenga $S$ (2013) When thyroid hormone replacement is ineffective? Curr Opin Endocrinol Diabetes Obes 20: 467-477.

4. Vaisman F, Coeli CM, Ward LS, H Graf, G Carvalho, et al. (2013) How good is the levothyroxine replacement in primary hypothyroidism patients in Brazil? Data of a multicentre study. J Endocrinol Invest 36: 485-488.

5. Canaris GJ, Manowitz NR, Mayor G, Ridgway EC (2000) The colorado thyroid disease prevalence study. Arch Intern Med 160: 526-534.

6. Jonklaas J, Bianco AC, Bauer AJ, Kenneth D Burman, Anne R Cappola, et al. (2014) Guidelines for the treatment of hypothyroidism: prepared by the American Thyroid Association Task Force on thyroid hormone replacement. Thyroid 24: 1670-1751.

7. Garber JR, Cobin RH, Gharib H, James V Hennessey, Irwin Klein, et al. (2012) Clinical practice guidelines for hypothyroidism in adults: cosponsored by the American Association of Clinical Endocrinologists and the American Thyroid Association. Thyroid 22: 1200-1233.

8. Morris JC (2009) How do you approach the problem of TSH elevation in a patient on high-dose thyroid hormone replacement? Clin Endocrinol 70: 671-673.

9. Hennessey JV, Malabanan AO, Haugen BR, Levy EG (2010) Adverse event reporting in patients treated with levothyroxine: results of the pharmacovigilance task force survey of the American Thyroid Association, American Association of Clinical Endocrinologists, and the Endocrine Society. Endocr Prac 16: 357-370.

10. McMillan M, Rotenberg KS, Vora K, Arnold B Sterman, Lionel Thevathasan, et al. (2016) Comorbidities, concomitant medications, and diet as factors affecting levothyroxine therapy: results of the CONTROL Surveillance Project. Drugs R D 16: 53-68. 
11. Soldin OP, Soldin SJ, Vinks AA, Younis I, Landy HJ (2010) Longitudinal comparison of thyroxine pharmacokinetics between pregnant and nonpregnant women: a stable isotope study. Ther Drug Monit 32: 767773.

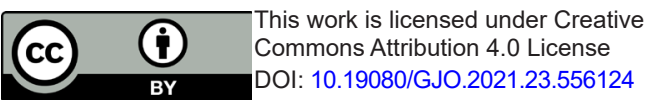

12. Singh N, Weisler SL, Hershman JM (2001) The acute effect of calcium carbonate on the intestinal absorption of levothyroxine. JAMA 283(21): 2822-2825.

\begin{tabular}{l} 
Your next submission with Juniper Publishers \\
will reach you the below assets \\
- Quality Editorial service \\
- Swift Peer Review \\
- Reprints availability \\
- E-prints Service \\
- Manuscript Podcast for convenient understanding \\
- Global attainment for your research \\
- Manuscript accessibility in different formats \\
( Pdf, E-pub, Full Text, Audio) \\
- Unceasing customer service \\
Track the below URL for one-step submission \\
https://juniperpublishers.com/online-submission.php \\
\hline
\end{tabular}

